\title{
Medication-related costs of rhinitis in Australia: a NostraData cross-sectional study of pharmacy purchases
}

This article was published in the following Dove Press journal:

Journal of Asthma and Allergy

9 May 2017

Number of times this article has been viewed

\author{
Pete Smith' \\ David Price ${ }^{2,3}$ \\ Richard Harvey ${ }^{4,5}$ \\ Andrew Simon Carney ${ }^{6}$ \\ Vicky Kritikos ${ }^{7}$ \\ Sinthia Z Bosnic-Anticevich 7,8 \\ Louise Christian ${ }^{9}$ \\ Derek Skinner ${ }^{10}$ \\ Victoria Carter ${ }^{10}$ \\ Alice Marie Sybille Durieux ${ }^{3}$ \\ 'Clinical Medicine, Griffith \\ University, Southport, QLD, Australia; \\ ${ }^{2}$ Observational and Pragmatic \\ Research Institute, Singapore; ${ }^{3}$ Centre \\ of Academic Primary Care, University \\ of Aberdeen, Aberdeen, UK; ${ }^{4}$ Applied \\ Medical Research Center, University \\ of New South Wales, Sydney, NSW, \\ Australia; ${ }^{5} \mathrm{Faculty}$ of Medicine and \\ Health Sciences, Macquarie University, \\ Sydney, NSW, Australia; ${ }^{6}$ Department \\ of Otolaryngology - Head and Neck \\ Surgery, Flinders University, Adelaide, \\ SA, Australia; ${ }^{7}$ Woolcock Institute \\ of Medical Research, University \\ of Sydney, Sydney, NSW, Australia; \\ ${ }^{8}$ Central Sydney Area Health Service, \\ Sydney, NSW, Australia; ${ }^{9}$ NostraData, \\ Kew, VIC, Australia; ${ }^{10}$ Optimum Patient \\ Care, Cambridge, UK
}

Correspondence: David Price Observational and Pragmatic Research Institute Pte Ltd (OPRI), 60 Paya Lebar Road, Paya Lebar Square, Level 5, Unit 33 $\& 34$, Singapore, 409051

Tel +65 68029724

Email dprice@opri.sg
Purpose: There is a relative paucity of research regarding medication expenditure associated with multiple-therapy use for rhinitis in Australia. To describe 1) the nature and extent of multiple-therapy use for rhinitis in Australia using data on therapies purchased with prescription or over-the-counter (OTC) and 2) additional costs incurred by multiple-therapy use compared with intranasal corticosteroid (INCS) therapy alone.

Patients and methods: A retrospective observational study was carried out using a database containing anonymous pharmacy transaction data available from $20 \%$ of pharmacies in Australia that links doctor prescriptions and OTC purchase information. Pharmacy purchases of at least one prescription or OTC rhinitis treatment, with or without additional asthma/chronic obstructive pulmonary disease (COPD) therapy, by patients during 2013 and 2014 were assessed.

Results: In total, 4,247,193 prescription and OTC rhinitis treatments were purchased from 909 pharmacies over 24 months. The majority of rhinitis therapy transactions were single-therapy purchases without additional asthma/COPD therapy. Of the single therapies purchased, $73 \%$ were oral antihistamines (OAHs) and 15\% were INCS therapy. Dual-therapy purchases of INCSs and OAHs accounted for $40 \%$ of multiple-therapy purchases. Patients frequently purchased OAHs, nonsteroidal nasal sprays, and eye drops for allergic conjunctivitis alongside INCSs, resulting in higher financial costs (up to AU\$21 per treatment episode) compared with INCS monotherapy. Conclusion: This study highlighted the significant burden posed on community pharmacy to address the needs of people with rhinitis symptoms, and the failure to translate the evidence that INCSs are the most effective monotherapy for moderate to severe and/or persistent rhinitis into clinical practice in light of the lack of evidence supporting combination of INCS and OAH therapy. Health care professional engagement, especially at the pharmacy level, will be extremely important if we wish to ensure that the purchase of rhinitis treatment is in accordance with guidelines and that their use is optimal.

Keywords: community pharmacy, intranasal corticosteroids, oral antihistamines, over-thecounter, prescription, rhinitis, therapy

\section{Introduction}

Rhinitis is not a single disease with one underlying mechanism but rather a collection of multiple distinct syndromes that cause similar nasal symptoms. ${ }^{1}$ Rhinitis is classified into two major subtypes - allergic rhinitis (AR), and a heterogeneous subgroup of conditions with various triggers and distinct pathophysiologies known as nonallergic rhinitis (NAR). Recent data suggest that as many as $87 \%$ of patients with rhinitis may have mixed rhinitis (MR), a combination of NAR and AR components. ${ }^{2}$ Untreated or suboptimally managed rhinitis can have a significant negative impact on patients' 
quality of life - impairments in work productivity, school performance, social interactions, and sleep. ${ }^{3-5}$ The high financial costs associated with inappropriately managed rhinitis, including the direct medication-related costs and indirect costs through lost wages and decreased productivity, pose a substantial economic burden on individuals and society. ${ }^{6,7}$

$\mathrm{AR}$ is the most prevalent form of rhinitis, affecting $10 \%-40 \%$ of the global population, and its prevalence is increasing both in children and in adults. ${ }^{3}$ In Australia, AR affects $17 \%$ of the population and is predicted to increase in prevalence by $70 \%$ in the next 35 years. ${ }^{8,9}$ Predominant symptoms of AR are sneezing, watery rhinorrhea, nasal itching, and nasal congestion. Other associated symptoms include postnasal drip, throat clearing, headache and/or facial pain, impaired smell, itchy throat and palate, and conjunctival symptoms. ${ }^{3,5,10-12} \mathrm{AR}$ is one of the most underestimated respiratory conditions, by both physicians and patients. Its management is often suboptimal as a result of delayed diagnosis, uninformed attempts by patients to self-manage with a wide range of over-the-counter (OTC) medication, or failure to engage a health care professional (HCP). ${ }^{9}$ Addressing this condition early can have significant clinical benefit, substantially improving the patient's quality of life while reducing the incidence and/or severity of comorbid disorders, including asthma, rhinosinusitis, otitis media, Eustachian tube dysfunction, and sleep apnea. ${ }^{3,10,11}$ Appropriate treatment can help contain costs by reducing absenteeism and presenteeism, decreasing complications of AR, and avoiding costly adverse effects of OTC medications. ${ }^{3,12,13}$

The Allergic Rhinitis and its Impact on Asthma (ARIA) guidelines propose an evidence-based stepwise approach to AR management based on the severity and duration of symptoms. ${ }^{3,10}$ Management strategies include minimizing allergen exposure, pharmacotherapy, and immunotherapy. ARIA guidelines recommend that pharmacological treatment should consider disease severity and duration; patient's preference; as well as the efficacy, availability, and costs of medications. ${ }^{3,10}$ Intranasal corticosteroids (INCSs) are recommended as first-line therapy for moderate to severe and/or persistent AR (as well as NAR), and are considered the most effective monotherapy for AR in both adults and children. They are effective in improving all symptoms of AR, including ocular symptoms, ${ }^{14}$ and are more effective than oral antihistamines (OAHs) in relieving nasal congestion. ${ }^{15,16}$ Second-generation OAHs are considered first-line therapy for mild intermittent AR, as they require once daily dosing and have a faster onset of action and fewer adverse effects than first-generation OAHs. According to ARIA, there is insufficient evidence to recommend the combined use of OAHs and INCSs, with most of the published studies showing no benefits gained by adding other AR treatments to INCS therapy. ${ }^{3,17,18}$

In Australia, data on the nature of prescription and OTC medication use for rhinitis, the extent of multiple-therapy use, and the costs associated with medication use in the real-life management of rhinitis are scarce. In 2010, the majority of OAH products available in Australia (125 out of 147) had OTC status, making 9 out of $10 \mathrm{OAH}$ products obtainable for single therapy or multiple-therapy use without consulting a pharmacist or medical practitioner. ${ }^{8}$ Multiple therapies are frequently co-prescribed for rhinitis, despite the lack of clinical evidence to support this practice, and can ultimately affect treatment costs to the patient. ${ }^{7,19-21}$ Owing to the current high availability of OTC rhinitis therapies, prior reports based on prescription data may underestimate multiple-therapy use.

This study was developed in order to provide more data on the burden of rhinitis in Australia as there is a relative paucity of research regarding medication expenditure associated with multiple-therapy use for rhinitis. Moreover, assessing medication expenditure may provide evidence for intervention in terms of both prescription policies and pharmacist counseling in OTC medications. The study aimed to describe 1) the nature and extent of multiple-therapy use for rhinitis in Australia using data on therapies purchased with prescription or OTC and 2) additional costs incurred by multiple-therapy use compared with recommended INCS therapy alone.

\section{Methods}

This was a cross-sectional observational study of a historical cohort conducted with data from a database collected during 2013 and 2014. The study was registered with the European Network of Centers for Pharmacoepidemiology and Pharmacovigilance (registration number ENCEPP/SDPP/8507), and approved by the Anonymised Data Ethics Protocols and Transparency (ADEPT) committee (approval reference number ADEPT0215).

\section{Data source}

NostraData (https://www.nostradata.com.au/Public/Home/ About) provided a demographically representative dataset of anonymous pharmacy transaction data that links doctor prescriptions and OTC information. In 2013, there were 5,240 pharmacies in Australia, with the three eastern seaboard states (Queensland, New South Wales and Victoria) accounting for $77 \%$ of the total number. ${ }^{22}$ The NostraData dataset included data from 909 randomly selected pharmacies throughout 
Australia and provided sufficient geographic coverage of the territory and the population, as shown in Table 1. Data within this dataset describe the details of valid transactions completed at the pharmacy, including name(s) of product(s) purchased, prescription or OTC status, postcode of purchase, and price paid. As the dataset does not contain patient demographic information or longitudinal data, it is not possible to track individual patient purchases at different NostraData pharmacies or on different occasions.

From the pharmacy claims dataset, we assessed pharmacy purchases of at least one prescription or OTC rhinitis treatment (used as a proxy for a diagnosis of rhinitis) with or without additional asthma/chronic obstructive pulmonary disease (COPD) therapy (used as a proxy for comorbid respiratory disease) during 2013 and 2014. Therapeutic classes of rhinitis treatments included OAHs, INCSs, intranasal antihistamine and corticosteroid combinations, nonsteroidal nasal sprays (NSNSs), leukotriene receptor antagonists (LTRAs), eye drops (EDs) for allergic conjunctivitis, oral corticosteroids, and injectable corticosteroids. A list of drugs included in each therapeutic class and the most representative in terms of prescription and OTC purchases is presented in Table 2. As LTRAs are likely to be purchased for asthma treatment rather than rhinitis, and given that individual patients could not be tracked in this dataset, LTRAs were included as rhinitis therapy only for pharmacy transactions without additional asthma/COPD treatment. Similarly, oral and injectable corticosteroids were included as rhinitis therapy only if they were purchased without additional asthma/COPD treatment. Therapeutic classes of asthma/COPD treatments included

Table I Sample characteristics of pharmacy transactions in different geographic regions of Australia over 24 months

\begin{tabular}{llll}
\hline State/Territory & $\begin{array}{l}\text { Pharmacies, } \\
\mathbf{n}\end{array}$ & $\begin{array}{l}\text { All } \\
\text { transactions, } \\
\mathbf{n}^{\mathbf{a}}\end{array}$ & $\begin{array}{l}\text { All transactions } \\
\text { including } \\
\text { rhinitis therapy, } \\
\mathbf{n}^{\mathbf{a}}\end{array}$ \\
\hline ACT & 30 & 379,839 & 215,527 \\
NSW & 235 & $2,405,577$ & $1,243,143$ \\
NT & 3 & 43,472 & 21,328 \\
QLD & 210 & $1,738,886$ & 870,898 \\
SA & 40 & 382,983 & 184,013 \\
TAS & 25 & 168,083 & 74,339 \\
VIC & 203 & $1,895,063$ & 907,978 \\
WA & 119 & $1,320,569$ & 729,967 \\
Total & 909 & $8,334,472$ & $4,247,193$ \\
\hline
\end{tabular}

Notes: andividual patients cannot be tracked in this dataset. The data shown are the number of pharmacy transactions.

Abbreviations: ACT, Australian Capital Territory; NSW, New South Wales; NT, Northern Territory; QLD, Queensland; SA, South Australia; TAS, Tasmania; VIC, Victoria; WA, Western Australia. short-acting $\beta_{2}$ agonists, inhaled corticosteroids, longacting $\beta_{2}$ agonists, inhaled corticosteroids and long-acting $\beta_{2}$ agonists combination therapy, short-acting muscarinic antagonists, long-acting muscarinic antagonists, cromones, and theophyllins.

\section{Study outcomes}

Medication-related outcomes for the period 2013 and 2014 included the following:

1. Count of therapies (ie, number of rhinitis therapies of distinct drug class purchased in the same transaction)

2. Drug class of rhinitis therapy purchased as single therapy in the transaction

3. Drug class of rhinitis therapy frequently purchased with INCSs in the same transaction

4. Proportion of different "classes of therapies" frequently purchased OTC with INCSs in the same transaction

5. Treatment cost of single therapy versus multiple therapy (ie, average price paid for single versus multiple-therapy purchases)

6. Treatment cost of different "classes of therapies" frequently purchased OTC with INCSs (ie, average price paid for single- versus dual-therapy purchases)

\section{Data analysis}

Data were analyzed using MySQL and Microsoft Excel 2011 software (Microsoft Corporation, Redmond, WA, USA). Descriptive statistics were used to summarize the sample characteristics of pharmacy transactions in Australia. Pharmacy purchases during the study period were analyzed together and reported as average numbers and percentages per calendar year. Count of therapies are presented as single, multiple, and total number of therapies, and reported as absolute numbers and percentages. Combinations of different classes of therapies are reported as absolute numbers and percentages. The cost of rhinitis therapy is calculated as the average price paid by patients in Australian dollars.

\section{Results}

Pharmacy transaction data from 909 pharmacies in 2013 and 2014 were assessed. Sample characteristics of pharmacy transactions in different geographic regions over 24 months are shown in Table 1 . Of the $8,334,472$ pharmacy transactions assessed, 4,247,193 (51\%) included rhinitis therapy. Of the $4,247,193$ pharmacy rhinitis therapy transactions, 4,074,496 (96\%) were without additional asthma/COPD therapy and 172,697 (4\%) were with asthma/COPD therapy. 
Table 2 List of drugs included in each therapeutic class

\begin{tabular}{|c|c|c|c|c|c|}
\hline Oral antihistamine (OAH) & $\begin{array}{l}\text { Intranasal } \\
\text { corticosteroid (INCS) }\end{array}$ & $\begin{array}{l}\text { Nonsteroidal nasal } \\
\text { spray (NSNS) }\end{array}$ & $\begin{array}{l}\text { Eye drop (ED) } \\
\text { for allergic } \\
\text { conjunctivitis }\end{array}$ & $\begin{array}{l}\text { Leukotriene } \\
\text { receptor } \\
\text { antagonist } \\
\text { (LTRA) }\end{array}$ & $\begin{array}{l}\text { Intranasal } \\
\text { combination } \\
\text { antihistamine/ } \\
\text { corticosteroid }\end{array}$ \\
\hline Acrivastine & $\begin{array}{l}\text { Beclomethasone } \\
\text { dipropionate }\end{array}$ & $\begin{array}{l}\text { Azelastine } \\
\text { hydrochloride }\end{array}$ & Nedocromil & Montelukast & $\begin{array}{l}\text { Azelestine/fluticasone } \\
\text { propionate }\end{array}$ \\
\hline Alimemazine tartrate & $\begin{array}{l}\text { Betamethasone } \\
\text { sodium phosphate }\end{array}$ & Ipratropium bromide & Lodoximide & Zafirlukast & \\
\hline Cetirizine & Budesonide & $\begin{array}{l}\text { Oxymetazoline } \\
\text { hydrochloride }\end{array}$ & Olopatadine & & \\
\hline Chlorphenamine & Flunisolide & Chromolyn & $\begin{array}{l}\text { Sodium } \\
\text { Cromoglycate }\end{array}$ & & \\
\hline Cyproheptadine hydrochloride & Flucticasone propionate & Antimuscarinic & & & \\
\hline Desloratadine & Fluticasone furoate & $\begin{array}{l}\text { Ephedrine } \\
\text { hydrochloride }\end{array}$ & & & \\
\hline Diphenhydramine & Mometasone furoate & $\begin{array}{l}\text { Xylometazoline } \\
\text { hydrochloride }\end{array}$ & & & \\
\hline Doxylamine $^{a}$ & Triamcinolone acetonide & $\begin{array}{l}\text { Sodium } \\
\text { Cromoglycate }\end{array}$ & & & \\
\hline Fexofenadine & & $\begin{array}{l}\text { Oxymetazoline } \\
\text { hydrochloride }\end{array}$ & & & \\
\hline Hydroxyzine hydrochloride & & Levocabastine $^{a}$ & & & \\
\hline Ketotifen & & Tramazoline $^{\mathrm{a}}$ & & & \\
\hline Levocetrizine & & & & & \\
\hline Loratadine & & & & & \\
\hline Mizolastine & & & & & \\
\hline Pheniramine $^{\mathrm{a}}$ & & & & & \\
\hline Promethazine hydrochloride & & & & & \\
\hline
\end{tabular}

\section{Count of rhinitis therapy drug classes in the same transaction}

Of the 4,247,193 pharmacy transactions that included rhinitis therapy, 4,074,987 (96.0\%) were transactions that included a single drug class, and 172,206 (4\%) were transactions that included multiple drug classes in the same transaction from pharmacies across all geographic regions of Australia (Table 3).

\section{Classes of rhinitis therapy as single therapy in the transaction}

Of the 4,074,987 pharmacy transactions that included a single drug class in the transaction from pharmacies across all geographic regions of Australia, 2,955,369 (73\%) were OTC and prescription purchases of OAHs, and 600,173 (15\%) were OTC and prescription purchases of INCSs (Table 4).

\section{Classes of rhinitis therapy frequently purchased with INCS in the same transaction}

Of the 172,206 transactions that included multiple drug classes in the same transaction from pharmacies across all
Table 3 Count of rhinitis therapy drug classes in the same transaction from pharmacies across all geographic regions of Australia $(\mathrm{N}=4,247,193)$

\begin{tabular}{ll}
\hline $\begin{array}{l}\text { Number of drug classes in the same } \\
\text { transaction }\end{array}$ & $\begin{array}{l}\text { Pharmacy transactions } \\
\mathbf{n}^{\mathbf{a}}(\%)\end{array}$ \\
\hline 1 & $4,074,987(96)$ \\
2 & $167,993(3.9)$ \\
3 & $4,150(0.1)$ \\
$\geq 4$ & $63(<0.001)$ \\
\hline
\end{tabular}

Notes: andividual patients cannot be tracked in this dataset. The data shown are the number of pharmacy transactions.

Table 4 Classes of rhinitis therapy as single therapy in the transaction from pharmacies across all geographic regions of Australia $(\mathrm{N}=4,074,987)$

\begin{tabular}{ll}
\hline $\begin{array}{l}\text { Class of } \text { rhinitis therapy purchased }^{\text {a }} \\
\text { as single therapy }\end{array}$ & $\begin{array}{l}\text { Pharmacy transactions } \\
\mathbf{n}(\%)\end{array}$ \\
\hline Oral antihistamine (OAH) & $2,955,369(73)$ \\
Intranasal corticosteroid (INCS) & $600,173(15)$ \\
Nonsteroidal nasal spray (NSNS) & $428,583(10)$ \\
Leukotriene receptor antagonist & $60,312(\mathrm{I})$ \\
Eye drop (ED) for allergic conjunctivitis & $29,054(0.7)$ \\
Intranasal combination therapy of & $\mathrm{I}, 496(0.03)$ \\
antihistamine and corticosteroid &
\end{tabular}

Notes: aver-the-counter and prescription. 
geographic regions of Australia, 68,840 (40\%) were joint purchases of OTC and prescription INCS and OAH (Table 5). The remaining 89,763 (52\%) transactions included purchases of other drug class combinations in the same transaction.

\section{Proportion of OTC "classes of therapy" frequently purchased with INCS in the same transaction}

Of the 72,592 OAHs, 9,769 NSNSs, and 3,673 EDs that were purchased OTC with multiple drug classes in the same transaction from pharmacies across all geographic regions of Australia, 68,237 (94\%) OAHs, 9,476 (97\%) NSNSs and 3,269 (89\%) EDs for allergic conjunctivitis were joint purchases with INCS (Figure 1). Purchases included OTC add-on therapy to INCS, and numbers may therefore differ from Table 3, which included OTC and prescription add-on therapy to INCS.

\section{Treatment costs}

The average cost to patients for purchases of multiple therapies was AU $\$ 40$ compared to AU $\$ 19$ for purchases of single therapy (Figure 2). The average cost of different "classes of therapies" frequently purchased OTC with INCS therapy is shown in Figure 3. The average (mean) price paid by patients for OTC OAH with INCS therapy was AU $\$ 45$ compared to AU\$31 for INCS monotherapy.

\section{Discussion}

This study provides a unique insight into the nature and extent of multiple-therapy use for rhinitis by patients in Australia during a calendar year, and the additional costs incurred by multiple-therapy use. It provides data on how rhinitis therapy is purchased, the prescribing practices of general practitioners (GPs), and self-medication behavior of patients in a real-world setting. Our findings revealed that the majority of rhinitis therapy transactions were single-therapy

Table 5 Classes of rhinitis therapy frequently purchased with intranasal corticosteroid in transactions that included multiple drug classes in the same transaction from pharmacies across all geographic regions of Australia $(\mathrm{N}=172,206)$

\begin{tabular}{ll}
\hline Class of rhinitis therapy purchased $^{\mathbf{a}}$ & Pharmacy transactions \\
with INCS & $\mathbf{n}(\%)$ \\
\hline Oral antihistamine & $68,840(40)$ \\
Nonsteroidal nasal spray & $9,731(6)$ \\
Eye drop for allergic conjunctivitis & $3,872(2)$ \\
\hline
\end{tabular}

Notes: ${ }^{a}$ Over-the-counter and prescription.

Abbreviation: INCS, intranasal corticosteroid.

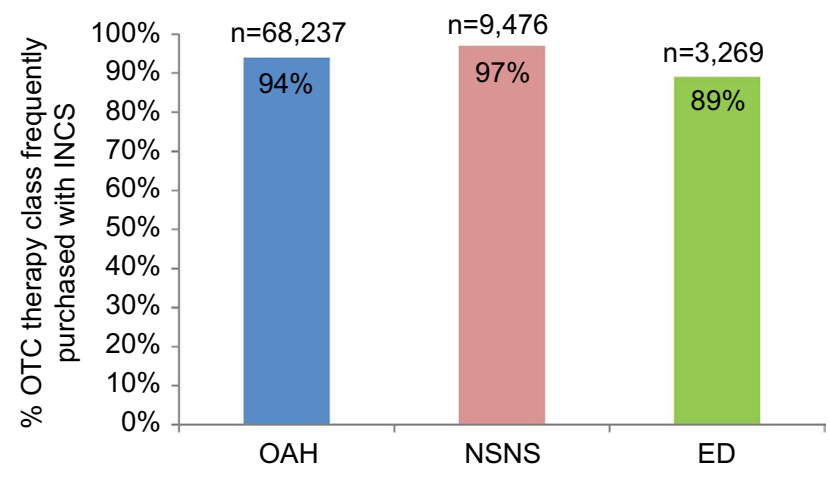

Figure I Proportion of OTC oral antihistamine $(\mathrm{N}=72,952)$, nonsteroidal nasal spray $(N=9,769)$, and eye drop $(N=3,673)$ frequently purchased with intranasal corticosteroid in the same transaction from pharmacies across all geographic regions of Australia.

Abbreviations: OTC, over-the-counter; INCS, intranasal corticosteroid; OAH, oral antihistamine; NSNS, nonsteroidal nasal spray; ED, eye drop.

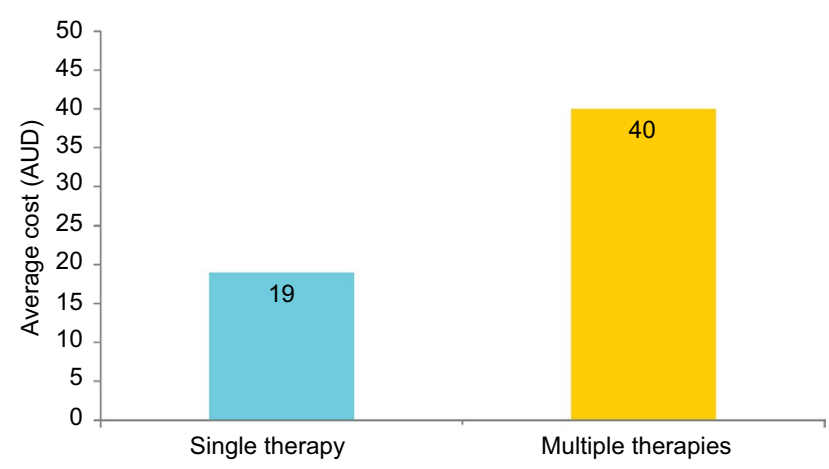

Figure 2 Average cost (AUD) of single versus multiple rhinitis therapies. Abbreviation: AUD, Australian dollars.

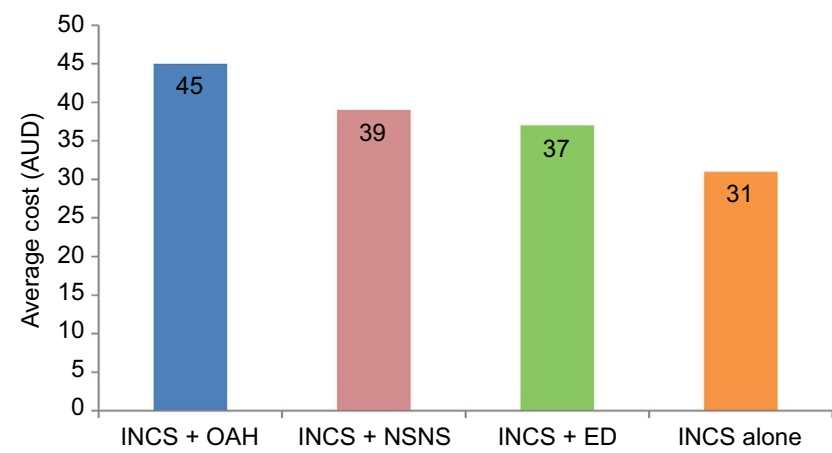

Figure 3 Average cost (AUD) of intranasal corticosteroid purchases with OTC: oral antihistamine $(\mathrm{N}=68,840)$; nonsteroidal nasal spray $(\mathrm{N}=9,731)$; eye drop for allergic conjunctivitis $(\mathrm{N}=3,872)$ versus intranasal corticosteroid monotherapy $(\mathrm{N}=600,173)$.

Abbreviations: AUD, Australian dollars; OTC, over-the-counter; INCS, intranasal corticosteroid; OAH, oral antihistamine; NSNS, nonsteroidal nasal spray; ED, eye drop.

purchases without additional asthma/COPD therapy. Of the single therapies purchased, $73 \%$ were OAHs, and only $15 \%$ were guideline-recommended INCS therapy. Dualtherapy purchases of INCSs and OAHs accounted for $40 \%$ 
of multiple-therapy purchases, despite the lack of evidence supporting this treatment combination. Patients frequently purchased OTC OAHs, NSNSs, and EDs for allergic conjunctivitis alongside INCSs, resulting in higher financial costs (up to AU\$21 per treatment episode) compared to INCS monotherapy, and potentially a greater overall cost burden due to the increased risk of costly adverse effects of inappropriate and injudicious medication use.

This is the first large-scale cross-sectional observational study assessing the nature and extent of multiple-therapy purchases for rhinitis from community pharmacies across Australia using prescription and OTC information. Research in this area has focused primarily on examining wholesaler supplies of rhinitis therapy to pharmacies, ${ }^{8}$ investigating demographics and medication use, and evaluating clinical and humanistic outcomes of individuals suffering with rhinitis symptoms who visit the pharmacy, using self-report questionnaire-based surveys without validation of the accuracy of the recording of treatments. ${ }^{20,21,23,24}$ Therefore, exploring the nature and extent of multiple-therapy use for rhinitis and associated costs incurred by patients, using valid prescription and OTC information, was considered important, given the increasing size of the OTC medicine market, the number of people with rhinitis who choose to self-medicate, the quality use of medicines in achieving optimal patient outcomes, and the paucity of data about the nature of prescription and OTC rhinitis therapy purchases from pharmacies in the Australian primary care setting.

The study revealed that the majority of rhinitis therapy purchases were single-therapy purchases, of which $73 \%$ were OAHs and $15 \%$ were INCSs. Our results are consistent with those from a 2001 longitudinal community pharmacy-based study in the United Kingdom (UK), which found that of the patient-reported treatments obtained for AR symptoms, over $70 \%$ were OAHs, and $14 \%$ were INCSs. ${ }^{20}$ The AR in Australia Report also found that almost three times as many OAHs as INCSs were supplied to pharmacies in 2010, and while 125 out of 147 OAHs had OTC status, only five out of 12 INCS products had OTC status, which could explain why people prefer purchasing OAHs as they are more readily available. ${ }^{8}$ Many people who initially present during the pollen season can still have symptoms six months later, suggesting that much AR that appears initially to be intermittent is in fact persistent in nature. ${ }^{20}$ Further, while the prevalence of mild and moderate to severe AR in Australia has yet to be determined, a community pharmacy-based survey conducted in Belgium found that $95 \%$ of survey participants had moderate to severe rhinitis. ${ }^{21}$ Although INCSs are regarded as the gold standard for treatment of moderate to severe and/or persistent AR by ARIA guidelines, ${ }^{3,10}$ and first-line treatment of NAR, ${ }^{11}$ a minority of individuals in our study purchased this class of medication. Underuse of INCSs has also been reported in the Asia-Pacific region, with $20 \%$ of Australians reporting a dislike for nasal sprays as the major reason for not using INCSs. ${ }^{25}$ Only $50 \%$ of Australians reported being very satisfied with their INCS treatment, and 50\% reported they had discontinued their INCS treatment. Major reasons cited for INCS discontinuation were lack of perceived effectiveness, diminution of effect with chronic use, and side effects such as retrograde drainage into the esophagus. ${ }^{25}$ As poor intranasal technique and nonadherence to regular continuous therapy are factors contributing to uncontrolled symptoms of rhinitis, appropriate tools and strategies will be needed to help overcome barriers and facilitate the quality use of medicines, as well as training and support for pharmacists involved in future delivery of pharmacy-based rhinitis care.

An interesting finding in our study was that a majority of rhinitis therapy transactions were without additional asthma/ COPD therapy. A possible explanation for this finding could be that a proportion of transactions without asthma/COPD therapy were by patients with undiagnosed respiratory conditions such as asthma and sinusitis, which are often associated with some types of rhinitis. ${ }^{3,10,11}$ In Australia, at least $30 \%$ of patients with known AR also have asthma, and up to $80 \%$ of people with asthma have coexisting AR. ${ }^{26}$ Both AR and NAR are risk factors for the development of asthma, ${ }^{27}$ and AR has been shown to be associated with worse asthma control in children and adults. ${ }^{28,29}$ Given that the upper and lower airway is regarded as "a united airway", ${ }^{30}$ ARIA recommends that in patients with persistent AR, health care providers should screen for asthma, and in those with asthma, they should screen for rhinitis. ${ }^{3,10}$ Other possible explanations for this finding were that a proportion of transactions without asthma/ COPD therapy were destined to individuals with chronic respiratory conditions or that most people with rhinitis and coexisting chronic respiratory disease may not manage their symptoms with pharmacotherapy but rather immunotherapy.

In this study, the most common multiple-therapy purchase was a combination of INCS and OAH, despite the lack of evidence supporting this treatment combination. ${ }^{3,10}$ This dual-therapy regimen has been observed in a large-scale retrospective study, ${ }^{31}$ which found that dual INCS and OAH therapy was common at the end of the UK pollen season (March-August), as initial OAHs or INCS monotherapy received at the start of the season proved to be insufficient in controlling symptoms for many AR patients. The study also 
found that monotherapy with INCS at the start of the season failed to control symptoms in about $25 \%$ of AR patients, a high proportion given their superiority of effect according to the guidelines. ${ }^{3,10,11,32}$ Factors that could contribute to failure of INCS monotherapy in controlling symptoms include mixed rhinitis, ${ }^{1,33}$ comorbidities, ${ }^{3,11}$ poor inhaler technique, ${ }^{32}$ polysensitization, ${ }^{34}$ nonadherence to long-term therapy, and severe chronic upper airways disease. ${ }^{35}$ For many AR patients, INCS monotherapy does not provide the expected level of relief, ${ }^{25,36}$ highlighting the need for pragmatic strategies to help improve long-term adherence, optimize intranasal device technique, as well as more effective AR treatment options.

Our study also found that patients frequently purchased OTC OAHs, NSNSs, and EDs alongside INCSs, resulting in higher financial costs (up to AU\$21 per treatment episode) for patients. AR is often regarded as a background noise, a nuisance, and a trivial disease, as it is not life threatening. For those reasons, AR is frequently self-managed by patients with OTC treatments from community pharmacies, and the pharmacist, therefore represents the first point of contact for advice on appropriate medication. ${ }^{19,37-39}$ Over $60 \%$ of rhinitis patients are known to self-medicate, often with inappropriate medication, leading to poorly controlled symptoms and suboptimal management. ${ }^{20,21}$ Multiple-therapy use is common among AR patients who often self-medicate with OTC treatments without seeking pharmacist advice. ${ }^{19-21}$ There appears to be a failure on the part of health care providers to translate the evidence that INCSs are the most effective monotherapy for moderate to severe and/or persistent rhinitis in both adults and children into clinical practice. INCSs are more effective than other therapies in improving all symptoms of AR, and quality of life, and are more cost-effective than other AR therapies. The study results highlight the need for HCP engagement, especially at the pharmacy level, which will be extremely important if we wish to ensure that the purchase of rhinitis treatment is appropriate and that their use is optimal. This is the only way to ensure that patients continue to use guideline-recommended medications appropriately.

\section{Strengths and limitations of this study}

This large dataset included pharmacy transaction data from 909 Australian community pharmacies and information on 4,247,193 rhinitis treatments for "real-life" patients with or without additional respiratory disease in 2013 and 2014. Data related to rhinitis therapy underwent rigorous quality assurance procedures prior to statistical analyses. As the dataset used prescription and OTC information, rather than patient-reported outcomes, it provided a unique insight into prescribing and self-medication behavior, and the significant burden posed on community pharmacy to address the needs of people with rhinitis symptoms. The sample of pharmacy transactions involving OAHs and INCSs treatments is representative of the Australian population as a whole based on the latest published data of pharmaceutical wholesale supply of OAHs and INCSs to community pharmacies. ${ }^{8}$ Finally, another strength of the study is its observational nature, which allowed a "snapshot" of the current state of rhinitis treatment purchases via prescription and OTC supply in Australia. This approach provides insight into prescriber behavior and patient purchasing behavior that would have been difficult to obtain through other approaches, such as online surveys, which can misrepresent patient and prescriber behavior.

The limitations of the study were associated with the cross-sectional design, lack of patient demographic data, and lack of longitudinal data, which may have resulted in an underestimation of multiple-therapy rates, as patients may not have purchased all their rhinitis therapies in the same transaction. In a longitudinal study of AR patients recruited through community pharmacies in the UK, $16 \%$ of patients purchased additional treatments from the pharmacy 5 days after their original purchase, and $16 \%$ and $18 \%$ purchased additional treatments after 4 and 8 weeks, respectively. ${ }^{20}$ Additionally, we used prescription and OTC purchases of rhinitis therapy as a proxy for a rhinitis diagnosis and asthma/ COPD therapy as a proxy for a diagnosis of asthma or COPD. There is, however, a possibility that treatments classified as rhinitis therapy could have been purchased OTC or by prescription for another indication such as eczema and allergic conjunctivitis, although a UK study has shown that $>60 \%$ of patients prescribed OAH had a diagnosis of rhinitis. ${ }^{40}$ Further, in this study it was not possible to check whether therapies purchased together in the dataset were all destined to the same patient, nor was it possible to document purchases or rhinitis therapy from pharmacies outside NostraData coverage. Another limitation was that we were unable to determine the cost burden associated with inappropriate use of medications, this being a major issue identified in this research. That is, although we were able to determine the unit costs of purchases, this does not mean that there was no additional cost burden due to the overall cost burden.

\section{Conclusion}

This large-scale retrospective observational study described the nature and extent of multiple-therapy use for rhinitis in a real-world setting and the additional costs incurred by multiple-therapy use compared with recommended INCS therapy alone. It highlighted the significant burden posed on community pharmacy to address the needs of people with 
rhinitis symptoms, and the failure to translate the evidence that INCSs are the most effective monotherapy for moderate to severe and/or persistent rhinitis into clinical practice. HCP engagement, especially at the pharmacy level, will be extremely important if we wish to ensure that the purchase of rhinitis treatment is appropriate and that their use is optimal.

\section{Disclosure}

Pete Smith has received honoraria from AstraZeneca, GlaxoSmithKline, Meda Pharmaceuticals, and Mundipharma.

David Price has board membership with Aerocrine, Amgen, AstraZeneca, Boehringer Ingelheim, Chiesi, Meda, Mundipharma, Napp, Novartis, and Teva Pharmaceuticals; consultancy with Almirall, Amgen, AstraZeneca, Boehringer Ingelheim, Chiesi, GlaxoSmithKline, Meda, Mundipharma, Napp, Novartis, Pfizer, Teva Pharmaceuticals, and Theravance; grants and unrestricted funding for investigatorinitiated studies (conducted through Observational and Pragmatic Research Institute Pte Ltd) from UK National Health Service, British Lung Foundation, Aerocrine, AKL Research and Development Ltd, AstraZeneca, Boehringer Ingelheim, Chiesi, Meda, Mundipharma, Napp, Novartis, Pfizer, Respiratory Effectiveness Group, Takeda, Teva Pharmaceuticals, Zentiva, and Theravance; payment for lectures/speaking engagements from Almirall, AstraZeneca, Boehringer Ingelheim, Chiesi, Cipla, GlaxoSmithKline, Kyorin, Meda, Merck, Mundipharma, Novartis, Pfizer, Skyepharma, Takeda, and Teva Pharmaceuticals; payment for manuscript preparation from Mundipharma and Teva Pharmaceuticals; payment for the development of educational materials from Novartis and Mundipharma; payment for travel/accommodation/meeting expenses from Aerocrine, Boehringer Ingelheim, Mundipharma, Napp, Novartis, Teva Pharmaceuticals, and AstraZeneca; funding for patient enrollment or completion of research from Chiesi, Teva Pharmaceuticals, Zentiva, and Novartis; stock/stock options from AKL Research and Development Ltd, which produces phytopharmaceuticals; owns 74\% of the social enterprise Optimum Patient Care Ltd, UK, and $74 \%$ of Observational and Pragmatic Research Institute Pte Ltd, Singapore; and is peer reviewer for grant committees of the Medical Research Council, Efficacy and Mechanism Evaluation Programme, and Health Technology Assessment.

Richard Harvey is a consultant for Medtronic, Neilmed, and Olympus, and has received honoraria from Sequiris and grant support from Meda Pharmaceuticals, Neilmed, and Stallergenes.

Andrew Simon Carney is a consultant for Olympus and Smith \& Nephew, and has received honoraria from Meda Pharmaceuticals.
Vicky Kritikos has received honoraria from AstraZeneca, GlaxoSmithKline, and Pfizer.

Sinthia Z Bosnic-Anticevich has received honoraria from AstraZeneca, Boehringer Ingelheim, GlaxoSmithKline, Mundipharma, and Teva Pharmaceuticals for her contribution to advisory boards/key international expert forum.

Alice Marie Sybille Durieux has conducted paid research in respiratory disease in the past 5 years on behalf of Aerocrine, AKL Research and Development Ltd, Almirall, Boehringer Ingelheim, Chiesi, GlaxoSmithKline, Meda Pharmaceuticals, Mundipharma, Napp, Novartis, Orion, Takeda, Teva Pharmaceuticals, and Zentiva. The authors report no other conflicts of interest in this work.

\section{References}

1. Bernstein JA. Characterizing rhinitis subtypes. Am J Rhinol Allergy. 2013;27:457-460.

2. Settipane RA, Kaliner MA. Chapter 14: Nonallergic rhinitis. Am J Rhinol Allergy. 2013;27(Supp1 1):S48-S51.

3. Bousquet J, Khaltaev N, Cruz AA, et al. Allergic Rhinitis and its Impact on Asthma (ARIA) 2008 update (in collaboration with the World Health Organization, GA(2)LEN and AllerGen). Allergy. 2008;63(Suppl 86):8-160.

4. Small M, Piercy J, Demoly P, Marsden H. Burden of illness and quality of life in patients being treated for seasonal allergic rhinitis: a cohort survey. Clin Transl Allergy. 2013;3:33.

5. Valovita E, Myrseth SE, Palkonen S. The voice of the patients: allergic rhinitis is not a trivial disease. Curr Opin Allergy Clin Immunol. 2008;8:1-9.

6. Hellgren J, Cervin A, Nordling S, Bergman A, Cardell LO. Allergic rhinitis and the common cold-high cost to society. Allergy. 2010;65: 776-783.

7. Meltzer EO, Bukstein DA. The economic impact of allergic rhinitis and current guidelines for treatment. Ann Allergy Asthma Immunol. 2011;106(Suppl 2):12-16.

8. Australian Institute of Health and Welfare 2011. Allergic rhinitis ('hay fever') in Australia. Cat. no. ACM 23. Canberra, ACT: AIHW.

9. Walls RS, Heddle RJ, Tang MLK, Basger BJ, Solley GO, Yeo GT. Optimising the management of allergic rhinitis: an Australian perspective. Med J Australia. 2005;182:28-33.

10. Brozek JL, Bousquet J, Baena-Cagnani CE, et al. Allergic Rhinitis and its Impact on Asthma (ARIA) guidelines: 2010 revision. J Allergy Clin Immunol. 2010;126:466-476.

11. Wallace DV, Dykewicz MS, Bernstein DI, et al. The diagnosis and management of rhinitis: an updated practice parameter. J Allergy Clin Immunol. 2008;122:S1-S84.

12. Marple BF, Fornadley JA, Patel AA, et al. Keys to successful management of patients with allergic rhinitis: Focus on patient confidence, compliance, and satisfaction. Otolaryngol Head Neck Surg. 2007;136:S107-S124.

13. Bousquet J, Neukirch F, Bousquet PJ, Gehano P, Klossek JM, le Gal M. Severity and impairment of allergic rhinitis in patients consulting in primary care. J Allergy Clin Immunol. 2006;117:158-162.

14. Howarth P. Antihistamines in rhinoconjunctivitis. Clin Allergy Immunol. 2002;17:179-220.

15. Passalacqua G, Canonica GW, Bousquet J. Structure and classification of $\mathrm{H}_{1}$-antihistamines and overview of their activities. Clin Allergy Immunol. 2002;17:65-100.

16. Nielsen LP, Mygind N, Dahl R. Intranasal corticosteroids for allergic rhinitis: superier relief? Drugs. 2001;61:1563-1579.

17. Anolik R. Mometasone Furoate Nasal Spray with Loratadine Study Group. Clinical benefits of combination treatment with mometasone furoate nasal spray and loratadine vs monotherapy with mometasone furoate in the treatment of seasonal allergic rhinitis. Ann Allergy Asthma Immunol. 2008;100:264-271. 
18. Esteitie R, deTineo M, Naclerio RM, Baroody FM. Effect of the addition of montelukast to fluticasone propionate for the treatment of perennial allergic rhinitis. Ann Allergy Asthma Immunol. 2010;105:155-161.

19. Demoly P, Allaert FA, Lecasble M. ERASM, a pharmacoepidemiologic survey on management of intermittent allergic rhinitis in every day general practice in France. Allergy. 2002;57:546-554.

20. Sinclair H, Bond C, Largue G, Price D, Hannaford P. Community pharmacy provision of allergic rhinitis treatments: a longitudinal study of patient reported outcome. Int J Pharm Pract. 2005;13:249-256.

21. Mehuys E, Gevaert P, Brusselle G, et al. Self-medication in persistent rhinitis: overuse of decongestants in half of the patients. J Allergy Clin Immunol Pract. 2014;2:313-319.

22. Retail and Personal Services (RAPS) Training Council. Community Pharmacy Enviromental Scan 2013. Available from: http://rapstc.com au/wp-content/uploads/2011/12/Community-Pharmacy-EnvironmentalScan-2013.pdf. Accessed February 22, 2017.

23. Lombardi C, Musicco E, Rastrelli F, Bettoncelli G, Passalacqua G, Canonica GW. The patient with rhinitis in the pharmacy. A crosssectional study in real life. Asthma Res Pract. 2015;1:1-6.

24. Lourenco O, Calado S, Sa-Sousa A, Fonseca J. Evaluation of allergic rhinitis and asthma control in a Portuguese community pharmacy setting. J Mang Care Pharm. 2014;20:513-522.

25. Katelaris $\mathrm{CH}$, Lai CK, Rhee C, et al. Nasal allergies in the Asia-Pacific population: results from the Allergies in Asia-Pacific survey. Am J Rhinol Allergy. 2011;25:S3-S15.

26. National Asthma Council Australia. Australia Asthma Handbook, Version 1.1. Melbourne, VIC: National Asthma Council Australia; 2015. Available from: http://www.asthmahandbook.org.au. Accessed September 14, 2016.

27. Passalacqua G, Ciprandi G, Pasquali M, Guerra L, Canonica GW. An update on the asthma-rhinitis link. Curr Opin Allergy Clin Immunol. 2004;4:177-183.

28. de Groot EP, Nijkamp A, Duiverman EJ, Brand PL. Allergic rhinitis is associated with poor asthma control in children with asthma. Thorax. 2012;67:582-587.
29. Price D, Zhang Q, Kocevar VS, Yin DD, Thomas M. Effect of concomitant diagnosis of allergic rhinitis on asthma-related health care use by adults. Clin Exp Allergy. 2005;35:282-287.

30. Bousquet J, Vignola AM, Demoly P. Links between rhinitis ad asthma. Allergy. 2003;58(8):691-706.

31. Price DB, Scadding G, Bachert C, et al. UK prescribing practices as proxy markers of unmet need in allergic rhinitis: a restrospective observational study. NPJ Prim Care Respir Med. 2016;26:16033.

32. Scadding GK, Durham SR, Mirakian R, et al. BSACI guidelines for the management of allergic and non-allergic rhinitis. Clin Exp Allergy. 2008;38:19-42.

33. Settipane RA. Other causes of rhinitis: mixed rhinitis, rhinitis medicamentosa, hormonal rhinitis, rhinitis of the elderly, and gustatory rhinitis. Immunol Allergy Clin North Am. 2011;31:457-467.

34. Ciprandi G, Cirillo I. Monosensitization and polysensitization in allergic rhinitis. Eur J Intern Med. 2011;22:e75-e79.

35. Bousquet PJ, Bachert C, Canonica GW, et al. Uncontrolled allergic rhinitis during treatment and its impact on quality of life: a cluster randomized trial. J Allergy Clin Immunol. 2010;126:666-668.

36. Hellings PW, Dobbels F, Denhaerynck K, Piessens M, Ceuppens JL, De Geest S. Explorative study on patient's perceived knowledge level, expectations, preferences and fear of side effects for treatment for allergic rhinitis. Clin Transl Allergy. 2012;2:9

37. Maurer M, Zuberbier T. Undertreatment of rhinitis symptoms in Europe: findings from a cross-sectional questionnaire survey. Allergy. 2007;62:1057-1063.

38. Fromer LM, Ortiz G, Ryan SF, Stoloff SW. Insights on allergic rhinitis from the patient perspective. J Fam Pract. 2012;61:S16-S22.

39. Storms W, Meltzer EO, Nathan RA, Selner JC. Allergic rhinitis: the patient's perspective. J Allergy Clin Immunol. 1997;99:S825-S828.

40. Smith P, Price D, Carney AS, et al. Oral antihistamine prescription as a proxy marker for rhinitis in the UK. 2015. Presented at Respiratory Effectiveness Group Summit; January 22-24; 2015; Rotterdam, The Netherlands.
Journal of Asthma and Allergy

\section{Publish your work in this journal}

The Journal of Asthma and Allergy is an international, peer-reviewed open access journal publishing original research, reports, editorials and commentaries on the following topics: Asthma; Pulmonary physiology; Asthma related clinical health; Clinical immunology and the immunological basis of disease; Pharmacological interventions and

\section{Dovepress}

new therapies. This journal is included in PubMed. The manuscript management system is completely online and includes a very quick and fair peer-review system, which is all easy to use. Visit http://www. dovepress.com/testimonials.php to read real quotes from published authors. 